
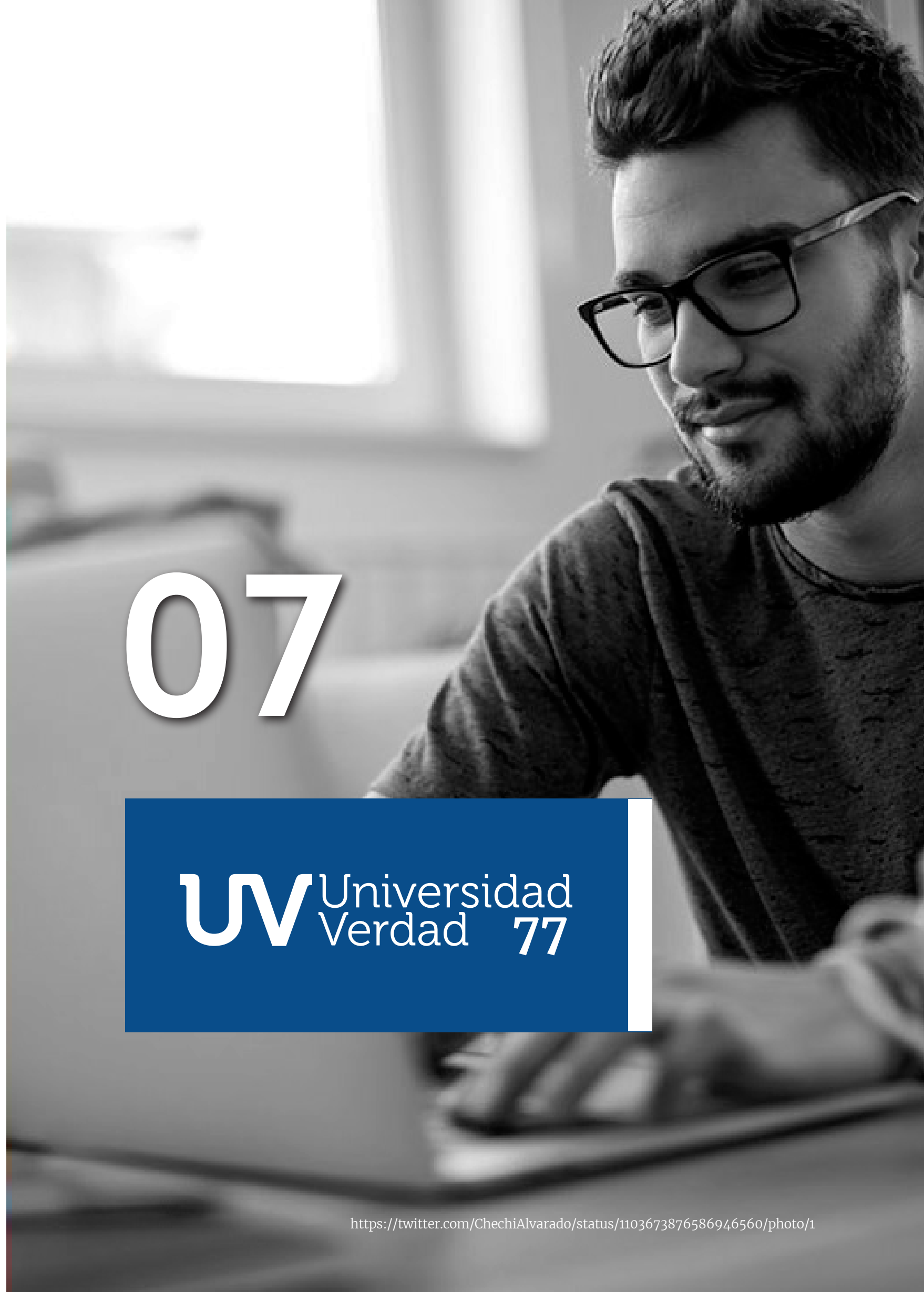

$\mathbf{W}$ Verdad $\mathbf{7 7}$ 


\title{
INTERSTICIOS (AUTO)BIOGRÁFICOS Y (AUTO) ETNOGRÁFICOS EN INVESTIGACIONES EDUCATIVAS. TRAMAS NARRATIVAS QUE ENTRELAZAN VIDA, FORMACIÓN Y DOCENCIA
}

\author{
(Auto)Biographical and (Auto)Etnographic interstices in \\ educational research. narrative plots that intertwine life, \\ training and teaching
}

\begin{abstract}
iD Luis Porta, PhD. Coordinador del Programa de Doctorado en Investigación Narrativa, Biográfica y AutoBiográfica en Educación de la Universidad Nacional de Rosario. (Argentina) (luisporta510@gmail.com) (http://orcid.org/0000-0002-5828-8743)

(iD) Aguirre Jonathan. $\mathrm{PhD}$, Docente e investigador del Departamento de Ciencias de la Educación de la Facultad de Humanidades/UNMdP. (Argentina)

(aguirrejonathanmdp@gmail.com) (http://orcid.org/0000-0002-6291-2545)
\end{abstract}

\section{Resumen}

Desde la segunda mitad del siglo XX asistimos a un viraje epistémico y metodológico producido en el marco del denominado giro narrativo en relación con los sentidos y fundamentos de la producción de conocimiento acerca de los mundos sociales, culturales y educativos, a partir de un retorno a los sujetos, sus discursos, prácticas e interacciones. En este contexto, y posicionados desde perspectivas pos cualitativas de investigación social, el enfoque biográfico-narrativo, emerge como una posibilidad de recuperar las experiencias vividas por los actores, resignificarlas a partir de sus relatos de vida y reinterpretarlas desde nuevos sentidos y significados. El artículo que aquí presentamos profundiza esta línea epistemológica recuperando los hallazgos de dos investigaciones realizadas en el seno del Grupo de Investigación en Educación y Estudios Culturales (GIEEC) sobre aspectos vinculados con la educación superior, la formación doctoral y la docencia universitaria. A partir de las voces y testimonios de investigadores en formación y de docentes de la Universidad Nacional de Mar del Plata, nos centramos en el valor biográfico de sus narraciones, en donde se pone de manifiesto la compleja y subjetivante amalgama entre vida, profesión y formación, evidenciada en el devenir de sus actos. Los hallazgos narrativos que presentamos se configuran en intersticios epistémicos-metodológicos potentes desde los cuales se puede habitar de un modo alternativo el campo de la investigación educativa, al tiempo que convida a producir desplazamientos, discusiones y debates futuros.

\section{Abstract}

Since the second half of the twentieth century we have witnessed an epistemic and methodological shift produced within the framework of the socalled narrative turn in relation to the meanings and foundations of the production of knowledge about the social, cultural and educational worlds from a return to the subjects, their speeches, practices and interactions. In this context, and positioned from post-qualitative perspectives of social research, the biographical-narrative approach emerges as a possibility of recovering the experiences lived by the actors, resignifying them from their life stories 
and reinterpreting them from new senses and meanings. The article that we present here deepens this epistemological line by recovering the findings of two investigations carried out within the Research Group on Education and Cultural Studies (GIEEC) on aspects related to higher education, doctoral training and university teaching. Based on the voices and testimonies of researchers in training and teachers of the National University of Mar del Plata, we focus on the biographical value of their narratives where the complex and subjective amalgam between life, profession and training evidenced is revealed in the future of their actions. The narrative findings that we present are configured in powerful epistemicmethodological interstices from which to inhabit the field of educational research in an alternative way, while inviting to produce future displacements, discussions and debates.

\section{Palabras clave}

Educación superior, investigación (auto)biográfico-narrativa, formación doctoral, docencia universitaria.

\section{Keywords}

Higher Education, (Auto) biographical-narrative research, doctoral training, university teaching.

1.

\section{Introducción}

Las variopintas formas que integran el espacio biográfico ofrecen un rasgo común: cuentan, de distintas maneras, una historia o una experiencia de vida. Dichas formas, "se inscriben así en una de las grandes divisiones del discurso: la narrativa" (Arfuch, 2010, p. 87). En este sentido, escribir o narrar sobre sí mismo adquiere significados fuertes en nuestras culturas y sociedades, en tanto parece advenir en los tiempos actuales a una vuelta al sujeto o al individuo, siempre en relación con los otros (Souto, 2016). Narrar(se), relatar las propias prácticas, la historia de formación, las figuras de formadores notables, los incidentes críticos, las situaciones problemáticas o exitosas vividas implica un trabajo personal de plegarse, replegarse y desplegarse uno mismo, de exteriorización de lo propio, al mismo tiempo que de incorporación de las perspectivas de los otros (Souto, 2016). Justamente ese proceso trataremos de mostrar en las próximas líneas.

A travñes del presente texto compartimos con la comunidad académica de Latinoamérica las potencialidades epistémicas, metodológicas y ontológicas que la narrativa (auto)biográfica (Arfuch, 2010; Delory Momberger, 2012; Porta, 2014; Souza, 2020) y los relatos (auto)etnográficos (Blanco, 2012; Guerrero-Muñoz, 2014; Ellis et ál., 2015) proporcionan a las investigaciones cualitativas (Denzin y Lincoln, 2015) y pos cualitativas (Hernández-Hernández, 2019) en el campo de la educación superior en Argentina.

Desde nuestro territorio académico más próximo y desde la labor de más de quince años del Grupo de Investigaciones en Educación y Estudios Culturales (GIEEC) radicado en el Centro de Investigaciones Multidisciplinarias en Educación de la Universidad Nacional de Mar del Palta, Argentina, asumimos al enfoque (auto)biográfico narrativo, más que como una mera herramienta metodológica, como una forma de pensar y comprender la realidad a partir de la cual los sujetos se construyen, se resignifican y se despliegan en el mundo (Porta y Yedaide, 2014; Ramallo y Porta 2020; Yedaide et ál., 2015). Es decir que 
recuperamos a la narrativa, principalmente, como fuente epistemológica y ontológica (García Huidobro, 2016). Textualización subjetiva que se configura en un saber que está enraizado en nuestras experiencias, en nuestros modos de relacionarnos y, en nuestro caso, en la manera en que nos posicionamos frente a la investigación y a la docencia universitaria.

Las narrativas (auto)biográficas, en este punto, permitieron a los participantes de nuestras investigaciones y a nosotros mismos, en tanto investigadores, volver reflexivamente sobre las experiencias vitales, formativas y profesionales, objetivándolas y resignificándolas en pos de construir conocimiento a partir de los relatos sobre nosotros mismos. El enfoque narrativo y biográfico, por tanto, nos posibilitó ir trazando, discontinuas pero enriquecedoras travesías de vida, de docencia y de investigación que se fueron entretejiendo con el correr de los años en nuestro grupo (Ramallo y Porta 2020).

Es así que se nos presenta lo narrativo no solo como una posibilidad para aprender, "desde las historias que contamos y reflexionamos sobre nuestra vida, sino como un aprendizaje contingente que sucede durante el proceso de quien se cuenta" (García Huidobro, 2016, p. 160). Es, en palabras de Ricouer, "la puesta en forma de lo que es informe adquiriendo relevancia filosófica y social al postular una relación posible entre el tiempo del mundo de la vida, el del relato y el de la lectura o escucha de esa narración" (1983, p. 152). Adoptar esta metodología en investigaciones socioeducativas, significa, por tanto, comprender la narrativa como camino y posibilidad que, por un lado, nos ayuda a cuestionar la realidad desvelando los posibles significados de lo vivido $\mathrm{y}$, por otro, se despliega como un espacio reflexivo para (re)pensarnos y (re)aprendernos, donde el investigador se incluye en el relato para ir dando cuenta del proceso a través de sus desplazamientos (Hernández-Hernández, 2019). Gracias a este conjunto de razones, por medio de estas narrativas - pese a su modo errático y único - es posible distinguir a través de nuevos ángulos "partes importantes de la condición humana pertenecientes al lado de dentro y de fuera, al derecho y al revés, a lo universal y lo local, a lo general y lo específico, a lo singular y lo plural; a las partes visibles y a aquellas que no se ven, a lo dicho y lo prohibido" (Rego, 2014, p. 135).
En el presente artículo compartiremos dos formas narrativas posibles de habitar lo (auto)biográfico y lo (auto)etnográfico en educación superior. Dos tipos de registros que se desplegaron como partes constitutivas de investigaciones emprendidas por el GIEEC en la Universidad Nacional de Mar del Plata. Una orientada hacia la formación de posgrado y la forma en que viven, sienten y se afectan aquellos estudiantes de nivel de doctorado cuando se embarcan en la empresa de cursar sus estudios posgraduales. Logramos habitar esos mundos íntimos gracias a los diarios (auto)etnográficos que investigadores del GIEEC fueron completando en la medida que avanzaban en sus investigaciones. Un relato en primera persona a partir de reflexividades, aprendizajes y desaprendizajes que la experiencia doctoral e investigativa les fue otorgando en su despliegue.

La otra narrativa que compartiremos está vinculada al trabajo de investigación que viene desarrollando el grupo con una docente de la Facultad de Humanidades de nuestra universidad, que ha sido elegida por sus estudiantes como una profesora memorable (Flores et ál., 2013; Porta y Álvarez, 2018) y que, a partir de diversos instrumentos biográficos y narrativos nos posibilitó reconstruir interpretativamente la amalgama que evidencian sus clases entre vida, profesión, cuerpo y subjetividad (Porta y Álvarez, 2018). En ambos casos nos ocuparemos de aquellos relatos que contienen en sus líneas textuales una urdimbre que conjuga investigación, formación, docencia y por sobre todas las cosas, afectaciones y emociones que nos sitúan en registros otros, susceptibles de ser indagados desde metodologías poscualitativas en educación (Hernández Hernández, 2019).

Así, la perspectiva epistémica metodológica post-cualitativa, biográfica y narrativa es asumida como una oportunidad para pensar el sentido de investigar desde lugares no siempre legitimados; desde una mirada que nos mueve de nuestras zonas de estabilidad, discute con posicionamientos tecnocráticos en educación y nos sitúa en una posición problemática que estimula el pensamiento y genera desplazamientos ontológicos, epistemológicos, metodológicos y éticos alternativos. Proponemos, al igual que Hernández-Hernández y Revelles-Benavente (2019), a lo post-cualitativo como una perspectiva que nos aporta una reconcep- 
tualización de las maneras de hacer y pensar la investigación y de cómo dar cuenta de ello. Una perspectiva que nos permite construir una investigación otra, que propugna reformular y repensar conceptos que han dominado la investigación clásica, y crear otros nuevos más allá de lo que las perspectivas modernas han marcado en el tiempo. Aquí es donde el espacio biográfico (Arfuch, 2010) recupera su máxima potencia, allí donde la construcción de los relatos por parte de sus protagonistas, nos aproxima a los procesos de generación de las identidades y las experiencias sociales de los sujetos y a las vinculaciones entre sus reflexividades, pruebas y soportes relacionales, materiales y simbólicos (Di Leo y Camarotti, 2013))

Estructuralmente el artículo que presentamos se cimienta en tres apartados interrelacionados entre sí. El primero de ellos apunta a reconstruir y profundizar las líneas metodológicas e instrumentales que vertebraron los dos tipos de investigaciones de nuestro equipo. En el segundo segmento, dividido en dos sub-partes, recuperamos la potencia de los relatos (auto)biográficos y (auto)etnográficos narrativos a partir de registros orales y escritos proporcionados por los protagonistas de las indagaciones. Finalmente, presentamos las principales reflexiones, preguntas y debates que moviliza el escrito. En ellas veremos las potencialidades del trabajo, sus límites y las posibles líneas de investigación que, consideramos, podrán abonar a las discusiones académicas y enriquecerán el diálogo al que convida el dossier que nos convoca.

\section{2.}

\section{Aspectos metodológicos. Enfoques, perspectivas e instrumentos}

Nuestras investigaciones se despliegan metodológicamente desde los enfoques cualitativos, poscualitativos, biográficos y narrativos en educación superior (Marradi et ál., 2018; Hernández-Hernández y Revelles-Benavente, 2019; Ogeda-Guedes y Ribeiro, 2019). De esta manera, dicha perspectiva alude a la multiplicidad y complejidad de nuestras experiencias y, a su vez, potencia una reflexión en acción que nos invitan a pensar los procesos inves- tigativos como enredos performáticos desafiando el carácter clásico, técnico y positivista que el campo de investigación socio-educativo ha ido retroalimentando en diferentes épocas (Denzin y Lincoln, 2015).

Ricoeur en su clásica obra Tiempo y Narración, se pregunta "¿Cómo hablar de una vida humana como de una historia en estado naciente, si no hay experiencia que no esté ya mediatizada por sistemas simbólicos, y entre ellos, los relatos, si no tenemos ninguna posibilidad de acceso a los dramas temporales de la existencia por fuera de las historias contadas a ese respecto por otros o por nosotros mismos?" (Ricoeur, 1983, p. 141). El autor nos invita a reflexionar sobre la narración y los relatos de experiencia entramando la vida con ellos. No hay vida sin relatos. La vida misma es narrativa textualizada en múltiples registros que se reconstruye y se resignifica permanentemente al simbolizarla en el lenguaje. Es desde este locus de enunciación que se comprende el sentido que las narrativas (auto)biográficas y (auto)etnográficas entraman en nuestras investigaciones educativas. Reconstruir biográfica y narrativamente las experiencias pedagógicas vitales (Porta y Yedaide, 2017) de los sujetos que transitan los cotidianos educativos universitarios nos coloca en dimensionalidades interpretativas que posibilitan visualizar la historicidad, territorialidad y socialidad (Porta y Flores, 2017) de las prácticas socioeducativas y los vínculos empáticos y afectivos desde los cuales los actores construyen y reconstruyen sus vínculos consigo mismos y con los otros.

Nuestro posicionamiento epistémico-metodológico se inserta, en definitiva, en el fenómeno que se ha producido en las últimas dos décadas y que Denzin (2017) lo define como una "impresionante proliferación e implosión de métodos biográficos interpretativos" (p. 82). El autor profundiza su descripción asumiendo que dichas perspectivas metodológicas se constituyen sobre la base, al mismo tiempo que van más allá, de las distintas versiones de historias de vida y estudios de casos biográficos que fueron los tópicos abordados en la clásica biografía interpretativa. Estas nuevas formas de trabajo biográfico incluyen, entre otras, la etnografía narrativa, la meta-autoetnografía (Ellis, 2009), autoetnografía (Holman et ál., 2013), y la autoetnografía performativa (Denzin, 2003). Emergen 
como conceptos claves de estas formas de habitar el espacio biográfico: la(s) narrativa(s), lo(s) significado(s), la(s) voz(es), la(s) reflexividad(es), la(s) presencia(s) y la(s) representación(es).

En este sentido lo poscualitativo también encuentra su máxima expresión ya que las representaciones y los formatos de textualización de experiencias de vida proliferan (Hernández-Hernández, 2019). "Sin problematizarse por las críticas contemporáneas que desafían términos como voz y presencia, cada vez más sujetos se vuelven hacia la historia oral, el mito, la (auto)etnografía y la narrativa performativa para hacer sentido de sus vidas, de ellos mismos, y de sus historias colectivas" (Denzin, 2017, p. 83).

Centrándonos en el aspecto instrumental, el GIEEC, en sus investigaciones se vale de una multiplicidad de recursos metodológicos en vistas a la recolección de los datos (Porta et ál., 2018). En la primera investigación que compartiremos, el instrumento utilizado por excelencia fue el "diario (auto)etnográfico narrativo" (Aguirre y Porta, 2019, p. 748). El diario autoetnográfico se configuró en sí mismo en una narrativa. Narrativa producida por el sujeto que investiga a los efectos de poder explicitar las diversas vivencias, sentimientos, interpretaciones que va registrando y sintiendo a lo largo, no solo del proceso de investigación, sino, particularmente, en el mismo trabajo de campo. Es, como argumentan los autores, un relato personal del investigador en donde explicita su propia subjetividad. "La narrativización de la vida en un autorrelato, textualiza la vida, textualiza las experiencias vitales y las convierte en un texto" (Bolívar et ál., 2001, p. 31). En el presente artículo compartiremos retazos de dos relatos (auto)etnográficos de investigadores del GIEEC que recientemente han concluido sus tesis doctorales y que han completado, durante todo el proceso investigativo, dichos diarios personales. Diarios que contienen lo etnográfico educativo (Rockwell, 2009) pero donde el yo autor se expresa en su máxima potencia y posibilita reconstruir narrativamente cómo las huellas de los maestros, la colectividad del equipo de investigación, las emociones, las alegrías, los miedos, los aciertos, las microdecisiones tomadas, los aprendizajes y los desaprendizajes se amalgaman configurando una potencia pedagógica para quienes inician el camino de formación e investigación doctoral y pueden leer lo que sus colegas han vivido previamente.
En cuanto a los retazos de la segunda investigación que compartimos emerge como principal instrumento de recolección de datos la entrevista en profundidad biográfica-narrativa (Fontana y Frey, 2015). Este tipo de entrevista se caracteriza por la intimidad e impersonalidad lograda en un tiempo prolongado de indagación entre el sujeto que investiga y el participante que narra (Guber, 2016). De alguna manera, la entrevista biográfica así planteada es "un proceso en el que se pone en juego una relación social, un encuentro entre dos subjetividades del cual surge una nueva" (Guber, 2016, p. 236). En estas entrevistas no se expresa simplemente una sucesión de acontecimientos vividos, sino la verbalización de una apropiación individual de la vida colectiva (Denzin, 2017).

Como anticipamos en la introducción del trabajo, aquí presentaremos las narrativas (auto)biográficas que surgieron de la última entrevista en profundidad que le realizamos a una docente de la carrera de Filosofía de la Facultad de Humanidades de nuestra universidad, que fue seleccionada por sus estudiantes, mediante la administración de más de 70 encuestas semi-estructuradas, como una de sus profesoras memorables. Memorabilidad que, como hemos desarrollado en otros trabajos (Flores et ál., 2013; Porta y Álvarez, 2018) radica en condiciones éticas, morales, empáticas, afectivas, eruditas, disciplinares e investigativas con las que cuentan estos profesores a la hora de desplegar sus clases universitarias y acompañar la formación de sus estudiantes, futuros docentes.

El GIEEC trabaja con dicha docente memorable (DM) desde el año 2008. La entrevista que contiene los retazos (auto)biográficos es la cuarta que hemos realizado en estos casi 10 años de labor investigativa. En este tiempo, potentes categorías analíticas emergieron de su relato, que nos posibilitaron definir a la "docencia como viaje odiseico, la enseñanza universitaria como aquella capaz de conjugar intelecto y afecto en su despliegue, al estudiante como un par antropológico, a la enseñanza como un modelo de instalación en el aula y en la vida, al humor como un recurso ludo-pático que potencia el aprendizaje, la pasión como motor y estilo constitutivo de la profesión: fuente y culmen de todo profesor memorable, y finalmente la dimensión corporal y la corporeidad como elemento indisociable de 
la enseñanza" (Porta y Álvarez, 2018, p.15). A continuación encontraremos ciertas profundidades a las categorías mencionadas anteriormente, pero observaremos más concretamente los diversos matices que asume la amalgama clase, cuerpo, vida y docencia en el relato (auto)biográfico de nuestra docente memorable. Retazos de intimidad que la enseñanza sigue poniendo en evidencia en la medida que uno se presta a percibirlos.

Cabe mencionar que todos los datos utilizados así como también cada uno de los instrumentos administrados han sido debidamente validados mediante el consentimiento informado de los participantes de las investigaciones. Cada uno de ellos ha revisado sus contenidos y los han autorizado para que el equipo de investigación los utilice. Producto de la intimidad de los relatos, resguardamos el anonimato de los participantes. Nos referiremos a ellos con los siguientes códigos. Registro Autoetnográfico $\mathrm{N}^{\circ} \ldots$ (RA $\mathrm{N}^{\circ} \ldots$... y Entrevista a Docente Memorable (EDM).

\section{3.}

\section{Hallazgos de investigación}

Retazos (auto)etnográficos de travesías formativas en la investigación doctoral. Biografía, aprendizajes y emociones narradas

Con el advenimiento de los métodos (auto)biográficos y (auto)etnográficos en las ciencias sociales, a mitad del siglo XX y, posteriormente, en las indagaciones educativas, se anuncia un periodo de resignificación de la subjetividad humana, donde las personas pasan del estatuto de objeto de análisis hacia el de sujeto protagonista de la investigación (Souza, 2020). De este modo, el sujeto pasa a "producir conocimiento de sí, sobre los otros y de la vida cotidiana, que se revela a través de la subjetividad, de la singularidad, de las experiencias y de los saberes, al narrar con profundidad" (Souza, 2006, p. 54). Fue en ese narrar que los investigadores del GIEEC encontraron la posibilidad de objetivar su propio proceso de investigación, sus travesías formativas en el nivel del doctorado, incluir esa narración como un instrumento más de recolección de datos potentes para sus trabajos, pero lo más importante, encontraron en la escritura del diario (auto)etnográfico un archipiéla- go catalítico cuya presencia, en muchos momentos del camino, los ayudó a textualizar sus miedos, temores, ansiedades, alegrías y emociones.

"Una experiencia única que me atravesaría durante meses. Que a cada paso me hacía replantear la manera en que llevaba adelante esa búsqueda, que me obligó a buscar un ancla que me protegiera de la marejada y que se tradujo en la inmersión en otra experiencia que no había previsto como lo fue el ejercicio de la autoetnografía. Ese diario de campo se convirtió en un barco de papel que contenía, como podía, el impacto que los relatos de los entrevistados primero, los intercambios posteriores y el trabajo con el material implicó en mi propia identidad". ( $\mathrm{RA} \mathrm{N}^{\mathrm{O}}$ )

"Hoy tuve la necesidad de comenzar el diario autoetnográfico que tanto nos recomendaron en el equipo a los que recién iniciamos el trabajo de campo de nuestras investigaciones doctorales. $\mathrm{Na}$ rrar mi experiencia, relatar mis pensamientos, traducir en lenguaje las emociones, los aprendizajes y los desplazamientos subjetivos en muchos momentos de la investigación me salvó. Fue ese bálsamo necesario para transitar las alegrías, las ansiedades, los miedos y la tesis...". (RA No ${ }^{\circ}$ )

"En mi caso, desde un primer momento, la tesis doctoral se volvió un constante viaje en sus diferentes instancias de concreción. Viaje que implicó ansiedad, nervios, inseguridades, pero al mismo tiempo inspiró confianza en mi director, en mis colegas y en mi propio trabajo de investigación. Un viaje que fue colectivo y solitario, tuvo momentos de serenidad y vértigo. Un viaje subjetivante y biográfico que asumió formas diversas de acuerdo avanzada en el caminar". (RA N $\left.{ }^{\circ} 1\right)$

"La importancia radica en el carácter performativo de la escritura que nos hizo depositar en ese diario el día a día de la indagación desde el momento en que inició el doctorado y hasta que logramos sumergirnos de lleno en el análisis de los datos. Este diario, además, se completa con las imágenes que necesitamos registrar cuando la escritura se veía completamente cooptada por la redacción de este informe final, que sin embargo seguía necesitando de esa instancia paralela de expresión. ( $\mathrm{RA} \mathrm{N}^{\circ} 2$ ) 
El diario completado por los investigadores en sus travesías doctorales se transformó tanto en instrumento metodológico como también en bálsamo subjetivante que les permitió habitar de una forma performática todo el proceso vivido. A diferencia de otros formatos, la autoetnografía narrativa, utilizando los materiales autobiográficos del investigador como datos primarios, enfatiza el análisis cultural y la interpretación de los comportamientos de los investigadores, de sus pensamientos y experiencias, habitualmente a partir del trabajo de campo, en relación con los otros. De esta forma, los autoetnógrafos reconocen las innumerables maneras en que la experiencia personal influye y transforma el proceso mismo de investigación (Denzin, 2017) reconociendo y dando lugar a su propia subjetividad, emocionalidad e implicancia en el trabajo de investigación (Ellis et ál., 2015).

Asumiendo entonces que la escritura (auto)biográfica y (auto)etnográfica habla, enuncia la subjetividad de quien escribe acerca de sí mismo y de sus prácticas es que presentamos los siguientes retazos de los diarios (auto)etnográficos de los dos investigadores de nuestro equipo, que se animaron a narrar su experiencia. Encontraremos relatos que no se exponen como modelos, muestran temporalidad, el proceso de devenir, el trabajo. No son lineales, sino "que toman la densidad de la experiencia vivida" (Souto, 2016, p. 49).

"Estoy a unas horas de concretar mi primera entrevista. Qué difícil fue concretarla. Los tiempos de uno, no coinciden, en ocasiones, con el de los demás y mucho menos con los de la investigación. Idas y vueltas de correos, mensajes... Soy consciente de que también se pone en juego mi ansiedad, creo que a lo largo de esta investigación deberé controlarla para que no se me vuelva en contra. (...) Continúo revisando el guion... otra vez". ( RA N $\left.^{0} 1\right)$

"El campo resultó mucho más fértil y generoso de lo que preveía, y cuando esperábamos la calma del trabajo intelectual de análisis, nos encontramos perdidas en un mar de relatos, documentos, mails, imágenes $y$ reflexiones desordenadas. Fue quizás ese diario el que logró, cómo un mapa que se dibuja mirando a las estrellas, orientar el camino para desandar y volver al puerto, para ordenar y producir un relato de identidades cruzadas en un ciclo de formación de futuros docentes. Lo que no pudo lograr es que ese marinero que zarpó fuera el mismo que regresó. $\left(\mathrm{RA} \mathrm{N}^{\circ} 2\right)$

"Nos encontramos en el café Sócrates de la calle Puan y Goyena, Ciudad de Buenos Aires. Inés se retiró unos segundos al baño antes de comenzar la conversación. Quedé solo en la mesa. Muchos nervios... primera entrevista. (...) Luego del diálogo nos despedimos. Me sentí muy desordenado, falto de repregunta y contenido Quizás si hubiera leído más... si hubiera analizado más documentos otro hubiese sido el resultado. Comienzan a aparecer los miedos y las dudas por mi objeto de estudio, mi perspectiva... Debo mejorar mucho si quiero avanzar en la tesis". (RA No ${ }_{1}$ )

"Nuevamente viajando a Buenos Aires Capital a realizar dos entrevistas importantes para mi investigación. Es diciembre y el calor se hace sentir en la ciudad porteña. Luego del viaje por subte me encuentro en el bar Leblé, lugar elegido para las entrevistas. Estoy más seguro que las últimas veces. La lectura, el análisis de los materiales, mi propia reflexividad ha ido cambiando. Siento que soy más paciente para repreguntar, puedo seguir la conversación que se dispara para otros temas, pero siempre vuelvo y encauzo el guion. Los datos comienzan a ser reveladores. (...) El resultado final aún es incierto pero que lindo es el proceso de indagación cuando uno es consciente de sus aprendizajes, mutaciones y crecimiento". ( RA N $^{0} 1$ )

"Otra de las enseñanzas que mi diario deja emerger es el carácter performativo del trabajo de campo. No sólo fue un antes y un después para mí en las huellas que dicho trabajo dejara, si no que los mismos entrevistados expresan la reflexión y el impacto que el recorrido por su trayectoria les produjo en las entrevistas y en los grupos focales". ( $\mathrm{RA} \mathrm{N}^{\circ} 2$ )

"Las idas y venidas sobre la construcción de los guiones y las dificultades al poner en acto esas entrevistas nos enseñó que ningún guion es lo suficientemente comprensivo si el entrevistador no agudiza su capacidad de escucha para dejar fluir los relatos y retomar los temas en el momento indicado. Que ningún guion es lo suficientemente potente para derribar las resistencias de los docentes a volver sobre cier- 
tos temas que consideran demasiado personales o dolorosos. Que solo es posible lograr la profundidad de la entrevista cuando se establece un vínculo con el entrevistado, que demanda de una mirada atenta, de involucrarnos en el relato y de abrir nuestras propias experiencias para dar espacio al diálogo en detrimento del monólogo". $\left(\mathrm{RA} \mathrm{N}^{\circ} 2\right)$

Delory Momberger sostiene que "nosotros los humanos, hacemos nuestra experiencia de vida en el tiempo y que no tenemos una relación directa, transparente con lo vivido y con nuestra propia vida, porque esa relación es mediatizada por el lenguaje y por sus formas simbólicas" (2012, p. 37). Así, "la narrativa es el lugar donde la experiencia humana toma forma, en ella se elabora y se experimenta en forma de una historia" (2012, p. 40). Los investigadores que narraron sus procesos investigativos, de alguna manera, volvieron a habitarlos en esos relatos. En ellos aparecen no solo las potencias metodológicas que otorgan, o los aprendizajes objetivados que permiten mejorar la práctica, sino que en los relatos aparece la vida íntima de los narradores, los padres, las parejas, los colegas. Los vínculos entretejidos entre vida, formación e investigación se evidencian en los retazos que compartimos y adquieren sentidos particulares al volver a narrativizarlos.

"Esta semana terminé el borrador del segundo capítulo de la tesis. Con ellos me di cuenta cómo uno va madurando e introduciéndose poco a poco en el tema de investigación. (...) Ayer mi novia me dijo algo que me encendió las alarmas: Que la tesis no te escriba a vos, vos ármala a ella. Que no te domine, vos dominala. Cuánta razón... pero qué difícil". (RA $\mathrm{N}^{\mathrm{O}} 1$ )

"El camino doctoral me regaló tiempo, aventuras y reencontrarme con mi padre desde otro lugar. Mario, mi papá, es conductor de un ómnibus de turismo que traslada pasajeros desde Mar del Plata a Buenos Aires y viceversa durante todo el año. Casi como una estrategia económica, yo trataba de combinar mis viajes a la capital para volver con él, si volvía sin pasajeros, o ir con él si debía buscar gente a Buenos Aires. Esa práctica de viajar con él hizo que fuera parte de mis vivencias investigativas. Desgrabaciones, miedos, ansiedades, tiempos de espera, consejos, un café compartido, una charla, fueron cimentando el detrás de escena de esta investigación". (RA No ${ }^{1}$ )
"Fue nuestro tercer encuentro y eso se nota. La confianza, entre investigador y entrevistado fue consolidándose a medida que el entrevistado se daba cuenta de la seriedad y el profesionalismo con el que uno trabaja como investigador. Aquí recupero lo que la bibliografía cualitativa plantea respecto al vínculo entre investigador e investigado. Mariana me recibió en su casa con una extrema hospitalidad. Allí no solo pude hacerme de fuentes de investigación sino que pude meterme en el corazón del tema objeto del estudio. Y con ello también Mariana fue ocupando un lugar central en mi trayectoria formati$v a$. Fue increíble". ( $\mathrm{RA} \mathrm{N}^{\circ} 1$ )

"La condición colectiva y afectiva del proceso de investigación, por lo menos en mi biografía doctoral, se constituyeron en pilares del trabajo y de mi formación doctoral. Soy consciente de que no siempre el doctorado y la investigación contienen estos pilares, por tanto me siento afortunada de haber podido contar con ellos. Por la sencilla razón de que me demostraron que uno no está sola en el mundo". ( RA N $^{\circ}$ )

Los relatos autoetnográficos que acabamos de mostrar se refieren a una temporalidad que oscila entre el pasado, el presente y el futuro. En dichas narrativas los autores trastocan el tiempo porque escriben en un presente que se refiere a los hechos sucedidos pero que al mismo tiempo los pone en condición de futurabilidad en virtud de sus aprendizajes, de sus deseos, de sus sueños y de sus temores a cumplirlos. "Un tiempo que es recuperado justamente en términos de deseo, de biografía, de proyección; es una concepción de sujeto incompleto, abierto a identificaciones múltiples a través de posiciones contingentes que es llamado a ocupar, pero siempre es un sujeto susceptible a ser auto-creado" (Porta y Álvarez, 2018, p. 33). En ese espacio de historicidad, socialidad y territorialidad en que los sujetos narran sus vidas en relación a su formación doctoral, sus avatares investigativos o sus rencuentros con ellos mismos y con sus familiares y colegas, "[la narrativa] contribuye a la habitabilidad de esa vida a partir de la textualización de su dimensión afectiva, emocional, institucional, profesional y los vínculos con los acontecimientos macrosociales" (Arfuch, 2010, p. 84). Esto es lo que de alguna u otra forma el diario autoetnográfico provoca a quien se anima a escribirlo en el despliegue de sus trayectorias de formación e investigación en el campo social. 
Retazos (auto)biográficos y narrativos de una profesora memorable. La clase, la transparencia, el cuerpo, las emociones y la vida.

La opción por la investigación (auto)biográfica, "en tanto dispositivo epistémico-metodológico, proviene de la posibilidad de -en el encuentro entre investigador-sujeto-autor - acceder a la vida de las personas, al prestar atención a las (re)significaciones de las experiencias personales, a las relaciones con el otro y con el contexto social" (Sousa, 2020, pp. 20-21). Tal abordaje metodológico forma parte de un extenso universo de investigaciones que utilizan las narrativas de los sujetos para valorizar la singularidad de sus vidas "a través de tomar la palabra como estatuto de singularidad, de subjetividad y de los contextos de los sujetos" (Souza, 2006, p. 27).

Los retazos narrativos y (auto)biográficos que nos otorga la docente memorable de nuestra investigación se conjugan no solo con nociones didácticas y pedagógicas potentes sino también con una forma particular de instalación en la clase universitaria. Un "modelo de instalación" (Porta y Álvarez, 2018, p.51) en donde se evidencia un especial vínculo con el estudiante, un respeto profundo por la disciplina enseñada, un compromiso con la clase, que trasciende la mera trasmisión de conocimiento y se sitúa en dimensionalidades afectivas y humanas.

Específicamente, en el siguiente conjunto de narrativas observaremos cómo la profesora, en el propio ejercicio de la docencia, recupera dicho modelo de instalación y con él las nociones didácticas vinculadas a la transparencia, al compromiso con el estudiante, a la ficcional teatralidad propia de la profesión y como esos condimentos didácticos-pedagógicos desplegados en el aula universitaria se amalgaman, se cruzan y se alimentan con su propia historia de vida, con su propia biografía. Habitaremos en su narrar una amalgama que nos sitúa en la clase, pero que al mismo tiempo nos proyecta y nos expande a condiciones vitales potentes y experiencias biográficas sensibles.

"El ejercicio docente es una forma de la entrega, de esa entrega afectiva, a fondo. Entonces también uno pone el cuerpo, pone otros elementos que la pura concatenación de ideas. Me parece que esa mezcla de la idea pero con los cuerpos, con la risa, con la escritura profusa sobre los pizarrones, esa cosa que llama a leer el pizarrón, a mirar al que está actuando y escucharlo, genera una exigencia... cuando uno va al teatro está exigido a seguir esa trama, esa música y esos cuerpos. (...) Yo quiero que los estudiantes en mis clases la pasen bien, y eso tiene que ver con brindar alguna forma de espectáculo para que lo pasen bien. Y la clase tiene que responder, es un compromiso asumido". (EDM)

"tengo una apuesta tan fuerte a esa posibilidad de que los alumnos se lleven todo de la clase, es una aspiración alta, por otra parte, que no siempre sale, indudablemente, no siempre debe salir, debe ser hasta saludable que así sea, pero...en mi juego, para ponerlo en el lugar del juego, en mi juego didáctico, yo intento que el alumno se apropie de la totalidad de la clase. Entonces esas advertencias, ojo con lo que viene, cuidado que aquí hay algo importante, hagamos una mínima crónica de lo que hicimos hasta ahora, porque lo vamos a remarcar, todas esas muletillas apuntan siempre a lo mismo si tiene que ver con la infancia, yo creo que sí, creo que tiene que ver con cosas no dichas en la infancia, creo que tiene que ver con cosas no dichas en esas tramas familiares, esos secretos familiares, creo que tiene que ver con la presencia de Aurora, en el interior de esa familia, donde no estaba claro exactamente que tenía, creo que tiene que ver con la oscuridad de la enfermedad de mi madre, que tampoco quedaba del todo claro, porque podía pasarse meses en la cama, en mí, con una necesidad de transparencia, una necesidad de juego claro, que creo que perfectamente puede anclar, allí. No saber exactamente como se llevaban mi papá y mi mamá, no saber exactamente porqué en una sociedad donde los roles estaban muy definidos, que no tenían el nomadismo ni la movilidad que los roles tienen ahora, porque era mi mamá la encargada de sacar a la calle los borrachos, y no mi papá, una serie de oscuridades, que yo las vivo como oscuridades, que creo que han determinado cierta instalación en la vida y en mi ser docente, cierta instalación en la vida, en la vida personal, en la vida profesional, donde me cuesta mucho que queden cosas que no te cuenten, absolutamente transparentes". (EDM)

"Es una escena casi teatral o cinematográfica, pero más teatral, donde se van corriendo como telones que 
van marcando el ritmo de la clase. Tiene que ver con las cosas que vendrán, con una transparencia en el juego. Por ejemplo cuando tengo que faltar o ausentarme en la clase siguiente por tener otro compromiso o porque no puedo viajar desde Morón a Mar del Plata tengo la obligación de anticipárselos. No me permitiría no aparecer. Entonces, cuando lo aviso, es, primero para que los alumnos sepan que no voy a estar, y segundo para que sepan lo que es la vida académica. Que hay algo del cuerpo que se traslada, algo del cuerpo que sale fuera de la universidad, que va a otras universidades, que va a otros países, que va a otros espacios, y que eso es la vida académica. Que en la vida académica hay algo nomádico, independientemente de la instalación en la clase.(...) Lo segundo tiene que ver con una cosa que a mí me obsesiona que es la transparencia en el contenido. Porque como lo hemos hablado muchas veces, yo entiendo que la apropiación de los alumnos del tema es un empoderamiento de los alumnos. Es hacerse cargo del poder del discurso del otro para poder generar un propio discurso. Por lo tanto los distintos tiempos, de la clase, y allí donde hay elementos fuertes en lo que se refiere al remate de una idea, o a la incorporación a la novedad de una idea, tiene que ver con esto, con el deseo de que el otro se apropie de cada momento de la clase". (EDM)

"yo quiero que las clases sean luminosas, luminosas, exactamente en ese sentido de que se vea claro. De que se me vea clara a mí, que no tengo dobleces, y que eso es algo que me importa mucho, y creo que eso se nota, y que retorna en el cariño que me tienen los alumnos". (EDM)

"Las clases nos llevan a interrogarnos a nosotros mismos por dónde estamos parados en el mundo, qué somos y cómo somos, para tener una perspectiva fresca sobre el mundo y cómo funciona tanto él como nosotros mismos en sociedad. Mi vida se define en parte por la universidad y, centralmente por la docencia. Ahí es donde yo digo que lo biográfico tiene un diálogo constante con la profesión y viceversa". (EDM)

El ejercicio de no intervenir con nuestra voz los retazos recuperados permite, por un lado, zambullirnos en los sentidos y los significados que la docente va entretejiendo de una forma textual que no es lineal, pero que, apreciados en un todo, percibimos esa amalgama respecto a la vida, la formación y la docencia puesta de manifiesto en las narrativas (auto) biográficas. Retazos que nos hablaron del ejercicio de la docencia y la necesidad de que el estudiante se apropie de la clase, que la habite, que la haga suya. Narrativas que nos pusieron frente al desafío de la transparencia en las prácticas de enseñanza, y cómo esa transparencia, en el relato particular de nuestra docente memorable, la lleva a su infancia, a recuperar, en la textualización de su vida, a su tía Aurora, el vínculo entre sus padres, el compromiso tácito de ser transparente, de no ocultar nada a sus estudiantes. Incluso la teatralidad que asume la profesión docente, la posibilidad de que esa teatralidad atrape al estudiante y le otorgue una oportunidad de interrogarse sobre el contenido de la obra, principalmente, sobre sus propios mundos, su propia vida.

Esta transparencia que produce luminosidad a la clase es central en la narrativa biográfica de la profesora, pero que puede constituirse también en elementos constitutivos de nuestra propia práctica de enseñanza en el nivel universitario. Allí radica uno de los aportes de esta tipología de indagación: introducirse en la experiencia narrada por otros para construir la nuestra desde sus dimensionalidades más potentes.

\section{4 .}

\section{Reflexiones finales. A propósito de la narrativa (auto)biográfica y (auto)et- nográfica: ¿De dónde venimos? ¿Quié- nes somos? ¿A dónde vamos?}

En 1897 el reconocido pintor francés Paul Gauguin, durante su segunda estancia en Tahití1, realizó el cuadro denominado "¿De dónde venimos? ¿Quiénes somos? ¿A dónde vamos?". En dicho fresco el artista buscó reflejar y metaforizar el escenario de la vida misma (Hernández y Revelles Benavente, 2019). A partir de esas tres preguntas se puede resumir la trama narrativa e histórica que configura la experiencia humana en su despliegue vital. Los relatos de vida, la (auto)biografización narrada por un sujeto tiende a habitar el pasado, resignificarlo a partir de la textua-

1 Isla de la Polinesia francesa, un territorio de ultramar francés localizado en las islas de la Sociedad, en el sur del océano Pacífico. 
lización experiencial presente y proyectar un futuro que aún no sucedió, pero que se gesta en su enunciación actual (Delory Momberger, 2012).

Desde estas territorialidades conceptuales, epistemológicas y metodológicas, las dos indagaciones que aquí se presentaron no se orientan a buscar resultados finales y concluyentes. No buscan la generalidad y la universalidad de historias, conductas o prácticas, sino que apelan a desvelar, problematizar y recuperar las voces íntimas de los sujetos a partir de sus relatos, que bien pueden tomarse en futuras indagaciones para producir dislocamientos teóricos y prácticos sobre los procesos formativos en el posgrado universitario y el ejercicio didáctico del quehacer docente. De ahí que el artículo se configure como un ensayo en vistas a pensar espacios de apertura y (re)aperturas a rutas imprevistas.

A partir de esas motivaciones, el texto se estructuró a partir de una introducción conceptual y epistémica sobre las investigaciones cualitativas, poscualitativas, biográficas y narrativas en el campo socioeducativo. Luego se presentaron los principales aspectos metodológicos de la investigación, como también su contextualización en nuestra comunidad académica más próxima, el Grupo de Investigaciones en Educación y Estudios Culturales (GIEEC) y, finalmente en el apartado de resultados/hallazgos mostramos las narrativas (auto)etnográficas y (auto)biográficas de dos investigadores en formación que concluyeron sus tesis doctorales en el año 2019 y compartimos, en segundo momento, retazos narrativos íntimos de una de las Docentes Memorables con la que el GIEEC ha trabajado los últimos 10 años y desde la cual pudimos recuperar la amalgama existente en su modo de ser profesora, la cual entrama biografía, cuerpo, emoción, transparencia, pasión y rigurosa erudición filosófica.

Diversas son las categorías analíticas que el artículo transita. En el primer segmento de hallazgos se desprende: El diario (auto)etnográfico como bálsamo catalítico, la escritura de sí como escritura performativa, el registro narrativo como posibilitador de ciertas objetivaciones en torno a los aprendizajes y desaprendizajes en la formación e investigación, la vida, los afectos y los vínculos que se entraman en dicha instancia doctoral. En lo que respecta al segundo apartado y desde los retazos de nuestra docente destacada, emergen con potencia categorías tales como: la entrega afectiva para con los estudiantes, el compromiso y la transparencia del contenido y del acompañamiento, la teatralidad y lo cinematográfico del ejercicio docente, los vínculos emocionales por momentos dolorosos- entre la infancia, las cosas no dichas en las tramas familiares y la enseñanza actual, la necesaria luminosidad de la práctica docente, en definitiva, el lector puede sumergirse en los retazos narrativos y encontrar allí lo que advertimos en el título del escrito: una indisoluble fusión entre vida, formación y docencia universitaria.

En una intervención acerca de la relación entre biografía y performatividad, nos interrogaron acerca de la utilidad de las investigaciones que realizamos en nuestro equipo; fue una interpelación a detallar los "impactos" o usos de la investigación narrativa para la pedagogía (Porta 2020). Nuestra respuesta osciló por múltiples caminos, pero se centró en la pérdida de la normatividad tecnocrática como el elemento por medio del cual las biografías expandidas permiten reconfigurar una nueva manera de pensar el campo pedagógico. Epistemológica, performática y (auto)biográficamente, "las biografías expandidas interrumpen en lo que es. (...) El trabajo con las biografías expandidas de los docentes e investigadores, o más bien sus propias vidas, posibilita abrir opciones de lo que es y lo que no es. Este también es el desafío para la investigación en educación: la encrucijada de escapar de lo estable" (Porta, 2020:30).

El debate que proponemos, entonces, es sobre lo imperioso que se vuelve irrumpir el campo de la investigación educativa contemporánea desde estos intersticios vitales. Asumir que la vida es narración (Ricoeur, 1983) y que recuperar esas narraciones tiene una doble potencialidad bien marcada. Por un lado, enriquece a quien la construye, porque desde ese tejido textual resignifica sus experiencias y trastoca temporalidades. Por otro, a quienes leemos esos relatos, nos regala la oportunidad de repensarnos y con ese ejercicio repensar el mundo que nos rodea. Por tanto, ya la pregunta no se orienta linealmente hacia ¿qué hacemos con esos relatos? Sino que nos disloca a pensar "¿qué hacen esos relatos con nosotros mismos?” (Porta y Ramallo, 2018, p. 87) 
5.

\section{Referencias}

Aguirre, J. y Porta, L. (2019) Sentidos y potencialidades del registro (auto)etnográfico en la investigación biográfico- -narrativa. Linhas Criticas. 25(1), 738-757. https://doi.org/10.26512/lc.v24i0.20077

Arfuch, L. (2010) El espacio biográfico. Dilemas de la subjetividad contemporánea. Buenos Aires: Fondo de Cultura Económica.

Blanco, M. (2012) Autoetnografía: una forma narrativa de generación de conocimientos. Andamios, 19(9), 49-74. https://ng.cl/04q1

Bolívar A. Domingo J. Fernández Cruz, M. (2001) La investigación biográfico- narrativa en educación. Enfoque y metodología. Madrid: La Muralla.

Delory Momberger, C. (2012) La condición biográfica: ensayos sobre la narrativa de si en la modernidad avanzada. Natal: EDUFRN.

Denzin, N. (2017) Autoetnografía Interpretativa. Revista Investigación cualitativa. 2(1). 81-90. 2017. http://dx.doi.org/10.23935/2016/01036

Denzin, N y Lincoln, I. (2015). Manual de investigación cualitativa, IV: métodos de recolección y análisis de datos. México: Gedisa.

Di Leo, P. y Camarotti, A. (2013) Quiero escribir mi historia. Vidas de jóvenes en barrios populares. Buenos Aires: Ed. Biblos

Ellis, C. (2009), Revision: autoethnographic reflections on life and work, Walnut Creek, California: Left Coast Press

Ellis, C. Adams, T. y Bochner, A. (2015). Autoetnografía, un panorama. Astrolabio, nueva época. 14(1), 249-273. https://n9.cl/ir42
Flores, G.; Álvarez, Z. y Porta, L. (2013): El profesor ideal: narrativas a partir de profesores memorables universitarios, Revista de Educación, 4(6). 215-230. https://ng.cl/1gwmo

Fontana, A y Frey, J. (2015). La entrevista: De una posición neutral al compromiso político. En: N. Denzin \& Y. Lincoln (eds.)Métodos de recolección y análisis de datos, 140-155. Barcelona: Gedisa.

García Huidobro, R. (2016) La narrativa como método desencadenante y producción teórica en la investigación cualitativa. EMPIRIA. Revista de Metodología de Ciencias Sociales. 34 (1) 155-178. https://doi.org/10.5944/empiria.34.2016.16526

Guerrero Muñoz, J. (2014) El valor de la autoetnografía como fuente para la investigación social: del método a la narrativa. Azarbe. 1(3), 237-242. https://n9.cl/totqz

Guber. R. (2016). La etnografía. Método, campo y reflexividad. Buenos Aires: Siglo XXI.

Hernández-Hernández, F. (2019). Presentación: La perspectiva postcualitativa y la posibilidad de pensar en 'otra' investigación educativa. Educatio Siglo XXI, 37(2) 11-20. https://doi.org/10.6018/educatio.386981

Hernández-Hernández, F., y Revelles Benavente, B. (2019). La perspectiva post-cualitativa en la investigación educativa: genealogía, movimientos, posibilidades y tensiones. Educatio Siglo XXI, 37(2), 21-48. https://doi.org/10.6018/educatio.387001

Holman J, Adams, E. y Ellis, C. (Eds.) (2013). Handbook of autoethnography. Walnut Creek, CA: Left Coast Press.

Marradi, A. Archenti, N. y Piovani, J. (2018) Manual de Metodología de las Ciencias Sociales. Buenos Aires: Siglo XXI.

Ogeda Guedes, A. y Ribeiro, T. (2019) Pesquisa, alteridade e experiencia. Metodologías Minúsculas. Rio de Janeiro, AYVU. 
Porta, L. (2014) Sentidos empáticos y reflexiones potentes sobre la Educación. Revista del IRICE. 26(1), 7-11. https://ng.cl/cimo6

Porta, L. (2020) Dislocar sentidos y producir movimientos sensibles. La expansión de lo biográfico en la performatividad de una pedagogía inestable. En: Porta, L. La expansión biográfica en educación. Buenos Aires: Universidad de Buenos Aires.

Porta, L. y Yedaide, M. M. (2014) Las narrativas de grandes maestros: hacia nuevas geografías del pensamiento y la formación docente. Revista Argentina de Educación Superior.9(6), 208-222. https://ng.cl/j2do8

Porta, L. y Yedaide. M. M. (2017). Pedagogías vitales. Cartografías del pensamiento y gestos ético-políticos en perspectiva descolonial. Mar del Plata. EUDEM.

Porta, L. y Flores, G. (2017). Investigación narrativa en educación: la expansión del valor biográfico. Revista Instituto de Investigaciones en Educación, 45(2), 35-46

https://doi.org/10.34096/riice.n41.5156

Porta, L. Aguirre, J. y Ramallo, F. (2018) La expansión (auto)biográfica: Territorios habitados y sentidos desocultados en la investigación educativa. Revista Interritorios, 4(7), 165-183. https://ng.cl/oxkr7

Porta, L. y Alvarez, Z. (2018). Pasiones; Cecilia Colombani. Mar del Plata: EUDEM

Ramallo, F. y Porta, L. (2018) La investigación narrativa en la historia de la educación: Desviaciones del relato del bachillerato argentino desde la inmediatez (Mar del Plata, 19141940). Cuadernos de la Facultad de Humanidades y Cs. Sociales 55(1), 85-100. https://ng.cl/u2gdd

Ramallo, F. y Porta, L. (2020) (In)visibilidades afectivas: Metodologías artísticas en la investigación narrativa. Revista Teias. 21(62), 439454. https://n9.cl/wkgse
Rego, T. (2014) Narrativas autobiográficas y la investigación sobre la trayectoria de los educadores. Tabanque Revista pedagógica, 27 (1). 129-146. https://n9.cl/eb187

Ricoeur, P. (1983) Tiempo y Narración. Tomo 1. Paris: Le Seuil.

Rockwell, E. (2009) La experiencia etnográfica. Buenos Aires: Paidós.

Souto, M. (2016). Pliegues de la Formación. Sentidos y herramientas para la formación docente. Rosario: Homo Sapiens.

Souza, E. C. (2006). O conhecimento de si: estágio e narrativas de formação de professores. Rio de Janeiro: DP\&A; Salvador: EDUNEB

Souza E. C (2020) Investigación (auto)biográfica como acontecimiento: contexto político y diálogos epistémico. Márgenes, Revista de Educación de la Universidad de Málaga, 1 (3), 16-33. https://doi.org/10.24310/mgnmar.v1i3.9613

Yedaide, M., Álvarez, Z. y Porta, L. (2015). La investigación narrativa como moción epistémico-política. Revista Científica Guillermo de Ockham, 13(1), 27-35. https://ng.cl/c64m 